\title{
How to be an Effective Technical Writer?
}

\author{
http://dx.doi.org/10.3991/ijep.v2i3.2094 \\ Dr. Dheya Al-Othmany, Dr. M. Solaiman Ali \\ King Abdulaziz University, Jeddah, Saudi Arabia
}

\begin{abstract}
This paper has focused on technical writing as a skill for engineers. It has sought to define technical writing and throw light on the content and technique of writing the various components of successful technical reports (for example, articles, papers, or research reports, such as theses and dissertations). Then, it has highlighted other special features and principles of effective technical writing. The material in this paper is divided into seven major parts. Part 1 (Technical writing for engineers) stresses that a successful engineering career requires strong writing skills. Part 2 (How to write the major sections or elements of a report) describes the techniques of writing the abstract, introduction, literature review, procedure/methods \& materials, results, discussion, conclusion, and recommendations. Part 3 (Special features of technical writing) brings into focus some of the special features of technical writing such as tables \& graphs in the text, graphics in instructions, team writing, ethics (plagiarism), document sources, three citation styles and IEEE reference style. Part 4 (Technical usage) deals with writing abbreviations, initialisms and acronyms, numbers, units of measurement, and equations. Part 5 (Technical style) highlights the imperative writing style and other features of technical writing such as the use of active and passive voices, plain vs. complex syntax, avoiding redundant or superfluous expressions, and vague generalities, using words or expressions with visual impact, the past tense to describe experimental work, the present tense to describe hypotheses, principles, theories and truths, and breaking up the text of the report into short sections. Part 6 (Document specifications) emphasizes the technical writer's need to conform to such document specifications as word count, format, font, number of words per line of text imposed. Part 7 (Reader-friendly technical writing) suggests choosing the varied writing modes (patterns of organization of information) to suit the technical writing task, checking for technical accuracy and following three levels of editing to help increase the readability of a technical text. Finally, in part 8 (Ethical/legal considerations for the technical writer), the authors suggest ways for the technical writer to overcome ethical/legal dilemmas on the job.
\end{abstract}

Index terms-Writing; research report; \&technical communication.

\section{INTRODUCTION}

This paper defines technical writing and explores organizational schemes and techniques used to write effective technical reports -- journal articles, conference papers, and research reports such as theses and dissertations.Technical reports are usually written by specialists for other specialists and report on the results of research and development. It is subject-specific prose writing."Technical writing” is the literature of science, technology, and systems development and is different from journalism, fiction, advertising, essays, plays, poetry, and other nontechnical prose. Traditionally, technical writers were thought of as engineering writers. Technical writers continue to be employed in such engineering-related industries as aerospace, defense, consumer electronics, chemical processing, pulp and paper, mining, construction, fiber optics, instrumentation and controls, and many other fields. [1]Technical writing usually deals with an object, process, system, or abstract idea, and the language isutilitarian (functional); it stresses accuracy rather than style. Good technical writing is technically accurate, useful, concise, complete, clear, and consistent, targeted, well organized, and must be correct in grammar, spelling and punctuation.

The technical content (information/message), not the writing style or author's feelings toward the subject, is the focal point. It is different from ordinary prose writing.

The skills and experiences of a composition teacher are useful to become successful as a technical writing teacher. The process approach used in teaching composition is the best way to teach technical communication, too. Second, both composition and technical communication are essentially rhetorical. Both are based on the premise that communication is addressed to an audience and intended to fulfil a purpose. Finally, both composition and technical communication focus on persuasion. [2] Therefore, the transition from composition to technical communication cannot be so difficult.

However, although composition and technical communication are both process-based and essentially rhetorical, there are two main differences in terms of emphasis. First, technical communication often leads composition in the use of technology. Second, technical communication focuses more on product: the size and shape of the finished document. Whereas the finished product in a composition class is often an essay, the products in a technical communication class are more likely to have counterparts in today's working world: sets of instructions, emails, reports,and so forth. And these documents are likely to be formatted to include multiple columns, headings, bulleted lists, and graphs, figures and tables. All these formattingfeatures are built into modern word-processing software. [2]

First, this paper throws light on the content and technique of writing the various components of a successful technical report. Then, it highlights other special features and principles of effective technical writing.

\section{TECHNICAL WRITING FOR ENGINEERS}

\section{A. A Successful Engineering Career Requires Strong Writing Skills}

Most of the successful engineers have towrite clear, well-organized memos and reports.Engineers who can't write well are definitely held back from career advancement. Opinions like this are common among engineering 
management. Many engineers spend more than 40\% of their work time writing, and usually the percentage increases as they move up the ladder. It does not matter that much of this writing is now sent through electronic mail (e-mail); the need for clear and efficient prose is the same whether it appears on a computer monitor or a sheet of paper. The vast body of technical information available in the world today has its genesis in the writing and speaking of engineers, whether they work alone or in teams. [3]

\section{B. Engineers Write Many Kinds of Documents}

The list of all possible engineering situations and contexts in which communication skills are needed is endless. Most technical documents conform to one of the following document types: memoranda, minutes of the meeting, literature reviews, reports, letters, proposals, press releases, specifications, documentation, instructions and procedures, style guides, theses, oral presentations, résumés, and notebooks. Electronic document types are: electronic mail (e-mail), websites and hypertext. [4]

Although different people approach writing tasks in different ways, there are some guidelines that engineering writers should follow for writing efficiently and producing useful documents. These guidelines in general follow the overall process used by successful engineering writers and include all the factors writers should consider from the time they first face a writing task to the point at which they have a final draft. [3]

The following section of the paper explores what content, skills and techniques go into writing each major section or element of common technical reports such as articles, papers, or research reports (e.g., theses anddissertations).

\section{How to Write THE MAJOR SECTIONS OF A REPORT}

What are the typical sections or elements of a technical report, especially a journal article,and research reports (including theses and dissertations)? Common sections or elements of a technical report are shown in the table below: [5]

\begin{tabular}{|cc|}
\hline Front matter & Body \\
$\bullet$ title\& title page & $\bullet$ introduction \\
$\bullet$ authorship and affiliation & $\bullet$ literature review \\
$\bullet$ abstract & $\bullet$ results, discussion \\
$\bullet$ keywords & $\bullet$ conclusion \\
$\bullet$ acknowledgements & $\bullet$ recommendations \\
$\bullet$ table of contents & $\bullet$ suggestions for future \\
$\bullet$ list of figures \& tables & research \\
$\bullet$ definitions of terms & End matter \\
$\bullet$ list of symbols & $\bullet$ references \\
& $\bullet$ appendices \\
\hline
\end{tabular}

Not each engineering document will require all of the sections or elements. Also, many companies require reports to conform to a particular format or style. If you have to write a report, check with your supervisor or technical publications department to see whether your organization has guidelines for technical reports [1].

These sections are typical, but the order may vary, and one or more may be omitted, depending on the length \& complexity of the report. However, technical report writers should familiarize themselves with the conventions of writing all the sections/elements in a report. In A Guide to Writing as an Engineer, authors David Beer \& David
McMurrey (2005)[3] describe a characteristic structureof the laboratory or field report.

In the case of writing the laboratoryand field reports which present not only the data derived from an experiment or survey and the conclusions that can be drawn from the data, but also the theory, methods, procedures, and equipment used in that experiment or survey. The laboratory or field report should enable readers to replicate the experiment so that they can verify the results for themselves. Because of this dual requirement, laboratory and field reports have a "characteristic structure" such as the following:

- Introduction, background and literature review

- Theory, methods, procedures, and equipment

- Results, findings, observations, or data

- Conclusion, implications and further research.

In Writing for Science and Engineering: Papers, Presentations and Reports, author Heather Sylin-Roberts(2000) [5]describes a similar structure using the acronym AIMRAD which stands for:

- Abstract

- Introduction

- Methods \& materials

- Results

- Discussion

The following is a description of how to write these major sections or elements of a technical report:

\section{A. Abstract}

The abstract is important for understanding the whole document. An abstract presents the overview to an expert audience. It is required in specialized documents such as journal articles, conference papers and posters. A journal article or paper abstract generally contains a maximum of300 words. [5], [6]

\section{B. Introduction}

You should succinctly describe the topic and define the scope of the report. You should also give the reader a clear idea of what material to follow. The introduction is one place that needs to be tailored to your specific audience, because the interest of each type of audience in your work will come from a different viewpoint. Briefly, review the literature and show the relationships between the various areas of work. Show the contributions of others, with correct reference citations of their work and provide a context for the later discussion of the results. In longer research reports (theses and dissertations), a separate chapter on the review of literature is required. [5], [6]In a short document, elements such as background, theory, objectives \&literature review can be included in the Introduction section.

\section{Literature review}

The purpose of a literature review is to demonstrate you have a good understanding of the history and current state of the topic. Give a coherent account of the various areas of research relevant to your topic. Give a historical account of its development. Summarize each study under review; identify the precise topic, methods/materials, results and recommendations. 
Show that you know who has done the relevant work, by citing names of the authors and the years in which the work was published. Show the links between the various areas of the body of knowledge - the correlations, contradictions, ambiguities and gaps. Show the weaknesses of other work and techniques and provide a summary of available techniques and materials. Show that your work will make an original contribution. A literature review is undertaken to identify methods and materials for the new study. [6]

\section{Methods \& Materials}

Describe your experimental procedure as precisely as possible. This will enable readers to judge the validity of your results in the context of the methods used. Describe your experimental design. Write as many of the details as possible so that the study can be replicated. [5], [3]

\section{E. Results \& discussion}

This section presents experimental data, observations, and results, along with a discussion of the meaning, significance, and application of these results. The common approach is to present the data, often formatted into tables, graphs, or charts, without interpretive discussion. [5], [6]

The discussion should present the principles, relationships, and generalizations supported by the results; point out any exceptions or lack of correlation; explain (if possible) why such exceptions or deviations occurred; and show how the results compare with results achieved by other researchers (results summarized in the review of literature). In this section, the author of the research report provides answer to the research question stated in the introduction, and explains how the results support the answer. This section will help the author to draw his/her conclusions. [1]

\section{F. Conclusion \& Recommendations}

Draw conclusions based on the data you have gathered and explain why you think those conclusions are valid. Write the conclusions as a series of numbered statements showing how the results answered the questions raised. Do not introduce new material in your concluding section. Your concluding section should be "crisp and clear" - you want to leave your readers with a solid understanding of what you have been discussing in the report. [7]On the basis of the results \& conclusions, the researcher can make recommendations about whether further research is needed or how the results can be applied commercially.

To sum up, these sections or elements of the technical report are typical, but the order may vary, and one or more may be omitted, depending on the length and complexity of the report.

In the sections that follow, some special features and principlesthat characterize effective technical writing will be highlighted.

\section{SPECIAL FEATURES OF TECHNICAL WRITING}

Technical writing is characterized by some special features such as use of tables and graphs, team writing, and ethical considerations. The function and how to use them in your document is described here.

\section{A. Use Of Tables And Graphics}

When engineering writers write reports, they are likely to need tables, illustrations, photographs, diagrams, draw- ings, charts, and graphs. Non-textual material like this inside the text helps the writer present information more effectively and gives a polished, professional look to the work. Tables, graphs and charts enable the writer to show data and, in particular, to show comparisons of data or changes in data. Photographs, drawings, and diagrams are all illustrative graphics, intended to represent physical things.[3]

Graphics in written and oral reports are invaluable aids to your audience because they condense text, clarify relationships, and highlight patterns. Good graphics display the significance of your data (which may be more exactly displayed in a table) and allow the reader to follow your discussion. Drafting graphics may also be a very effective way to help you draft a long written report or oral presentation. [4]

With the increasing power and ease of use of graphics software applications, engineering writers do not need to be graphics professionals to create or adapt graphics for engineering reports or documents. However, when the writer incorporates tables and graphics into a report, he/she has to pay attention to standard components, their placement, and cross-references to them. The writers should familiarizehimself/herself with guidelines for designing and incorporating tables and graphics into the text. Such guidelines provide instructions for how to label them accurately, number them consecutively, and integrate graphics and text.

\section{B. Graphics In Instructions}

Graphics are usually essential in instructions. Sometimes words cannot convey enough detail about key objects and key actions in a procedure. For example, just how does part A fit into part B? Make a list of the key objects and the key actions in your instructions, and identify those that readers might have trouble with. These are the ones for which you may need graphics.

\section{Team writing}

Technical people work together as teams for research, design, development, and testing, and often find they must team up to write proposals, manuals, completion reports, and a lot of other technical documents. [3]Team writing is not always easy, especially, when people with different degrees of writing ability or ego are involved, or when team members are torn between team responsibilities and other duties. If your group plans the team project carefully, however, it can turn out to be relatively painless and very rewarding because as a team you will be tapping into far more knowledge, skill, and creativity than you can bring to a project alone.

When you work on a team project, you should be prepared to demonstrate such attitudes as: communicate, coordinate, collaborate, cooperate, and compromise. Although the list might seem obvious, many teams fail to reach their potential because some members have difficulty following it. Beer \& McMurrey (2005) suggest three practical ways of how a team can produce a written document. The three methods, from the least preferable (but most commonly used) to the most effective, are as follows:[3]

1. Divide the length of the assignment by the number of people involved, and get each to write his or her share. 
2. Have one person organize the material, write the entire draft, edit it, and pass the finished product on to the next member of the team. This person will add, delete, rearrange, and re-edit as he or she sees fit. The third member of the team will do the same, and so on down the line.

3. Assign each member to different tasks according to that member's strength and weaknesses.

Using this method, everyone on the team can bring particular strengths to the task and play a significant role in producing the document. Each person has direct access to the document manager, knows what the others' responsibilities are, and has the satisfaction of being uniquely involved in the job. Whatever the situation, though, carefully planning and assigning collaborative writing tasks to team members before the writing project begins will result in a more efficiently produced document that is both coherent and useful. [3]

\section{Plagiarism}

If as an engineer you knowingly or unknowingly poachthe language, ideas, thoughts, or graphics of others, representing them as your own original work by failing to acknowledge your sources, you are plagiarizing. You might even be infringing on someone's intellectual property rights, and thus could open yourself up to the possibility of lawsuits. Plagiarism is frequently the result of ignorance or carelessness rather than dishonesty. Some writers and researchers simply get lazy: It is easier to replicate another's ideas or style than to think about what you have read and then put it in your own words and reference it. However, when you do research, all information that you obtain from journals, books, the Internet, and so on, must be fully documented - that is, accompanied by references to the sources where you obtained the information. Only your own ideas and opinions, plus "common knowledge," need not be referenced. [3]

\section{1) Reference style}

For both the "in-text" and "works cited page" documentation, there are strict rules about what information to include, in what order it should be given, and how it is to be punctuated. Although many researchers and writers seem baffled by these rules, the reason for this "pickiness" is to reduce confusion by having everyone conform to the same conventions. Documentation rules establish a uniform, universal format so a reader can quickly determine what type of source is being cited and, if desired, track down the text. [6]

\section{2) Which reference style to choose?}

Before you start writing, it is a good idea to find out the recommended citation style used in your profession. Different disciplines and even different publications within a discipline vary in specific stylistic details. The following three styles, however, provide commonly used examples of each of these general formats. [4]

1. Parenthetical short text references linked to a list of references

a. American Psychological Association (APA) style

b. Modern Language Association (MLA) style

2. In-text numbers linked to a list of references

a. Council of Biology Editors (CBE) citation-sequence system b. Institute of Electrical and Electronics Engineers (IEEE) reference style

3. In-text numbers linked to footnotes or endnotes with or without a list of references

a. Chicago Manual of Style (CMS) Note Format: the standard note system, which has been adapted for students by Kate Turabian in A Manual for Writers of Term Papers, Theses, and Dissertations.

\section{3) IEEE reference style}

The technical writer must familiarize himself/herself with the reference style recommended in his field or organization. IEEE reference style is a very well known and widely used one. The Institute of Electrical and Electronics Engineers (IEEE) is one of the largest professional organizations in the world, and it oversees numerous journals and regularly publishes its own Letters, Transactions, and Proceedings of the technical conferences it sponsors. IEEE reference style guide -- IEEE Transactions, Journals, and Letters: Information for Authors(2006) -- is available online. [http://www.ieee.org/portal/cms_docs/ pubs/transactions/auinfo03.pdf.]

The guide includes a brief but concise outline of the IEEE reference style, which is a variation of the CBE Citation-Sequence (C-S) system.IEEE style, like CBE style, uses a single sequentially ordered note number to cite all references in the text. Like the one in the CBE C-S system, the IEEE referencelist is arranged by the order of citation in the text, not in alphabetical order.[4]

\section{TeChnical Usage}

Technical usage implies knowing how to write abbreviations/acronyms, numbers, units of measurement, and equationsin the technical report.

\section{A. Abbreviations}

Abbreviations are necessary in technical communication for the same reason valid technical jargon is. They refer to concepts that would take a great deal of time to spell out fully. Therefore, the technical report writer, should always spell abbreviations out the first time he/she uses them unless they are too obvious.

\section{B. Initialism \& Acronyms}

Abbreviations can be subdivided into initialisms and acronyms. Initialisms (sometimes called initializations) are formed by taking the first letters from each word of an expression and pronouncing them as initials, for example, GPA, IBM, LED, and UHF. Acronyms are also created from the first letters or sounds of several words, but are pronounced as words: AIDS, FORTRAN, NASA, RAM, and ROM. Some acronyms become so well known that they are thought of as ordinary words and written in lowercase: bit, laser, pixel, radar, scuba, and sonar. Many engineering writers no longer observe the distinction between the two, and call any abbreviation an acronym. [3]

Two usage pointers: Use the correct form of a/an before initialism. Second, form the plural of acronym and initializations by a lowercase s. Only put an apostrophe between the abbreviation and the $\mathrm{s}$ if you are indicating a possessive form, for example,

- We ordered three CRTs.

- We weren't satisfied with the performance of the latest CD-ROM. 


\section{Numbers}

The field of engineering involves using a great deal of numbers. Frequently, this is where a lot of "written noise" occurs due to typos, incorrect or inexact numbers, and inconsistencies. To avoid noise from inconsistent use of numbers, Beer \& McMurrey (2005) provide some guidelines (such as the following) that engineering report writers should follow: 1 . Numbers are expressed as words or numerals. Cardinal numbers are written as one, two, three, etc. Ordinal numbers are written as first, second, third, etc. It is a good idea to write the cardinal numbers from one to ten as words and all other numbers as figures (numerals). When more than one number appears in a sentence, write them all the same. Also, use numerals rather than words when writing time, money, or measurements.2. If a number begins a sentence, spell it out (as a word).3. When expressing very large or small numbers, use scientific notation. [3]

\section{Units Of Measurement}

Although the public in the US is still not committed to the metric system, in general, the engineering profession is. Two versions of the metric system exist, but the more modern one, the SI (Fr. Système international) is preferred. The vital rule is to be consistent. Do not mix English and metric units unless you are forced to. Be sure to use the commonly accepted abbreviation or symbol for a unit if you do not write out the complete word, and leave a space between the numeral and the unit.

When working with very large or very small units of measurement, you will need to be familiar with the designated SI (Fr. Système international) expressions and prefixes.

A recent dictionary of scientific terms will guide you if you are unsure of the correct spellings or symbols of the units you are using.

\section{E. Equations}

Equations can communicate ideas far more efficiently than words can at times - consider the ideas represented by $E=m c^{2}$, for example. However, formulae and equations slow down your reader, so use them only when necessary and when certain audience can follow them. Many word processing programs now make it easy to write equations in text, but if you have to write them in longhand, do so with care to ensure both accuracy and legibility. An illegible or ambiguous equation is hardly going to communicate data effectively, and an error in an equation could be grave. In other words, make sure your equations are noise-free.

Eventually, you may have to incorporate multiline equations into your technical papers and reports, where they will read just like sentences. No material is too complex to be presented clearly in a flowing, natural manner. Further, punctuation, transitions, accurate grammar, and mechanics are all indispensable tools for conveying highly technical informationin a comprehensible manner.

\section{TECHNICAL STYLE}

What constitutes technical style? Technical writing usually follows the imperative writing style in which many sentences use the imperative form (for example, "Press the Enter key") or are phrased with the word "you" (for example, "You should check the temperature of the....") the....”) In this "in-your-face" style of writing, the author addresses the readers directly and gets their full attention, and is straightforward about what they are supposed to do. [3] Further, for effective communication of information, writers should take into consideration certain otherprinciplesof technical writing: using the active voice [although technical writers generally use the passive voice sentences]; using plain rather than elegant or complex language; deleting words, sentences, and phrases that do not add to your meaning; using specific and concrete terms rather than vague generalities; using terms your readers can picture; using the past tense to describe your experimental work and results, and the present tense to describehypotheses, principles, theories, facts and other truths; keeping ideas and sentence structure parallel; making the technical depth of your writing compatible with the background of your reader (so they can understand you); breaking up your writing into short sections; and so on. [3]

\section{DOCUMENT SPECIFICATIONS}

For publication of engineering documents, various specifications apply. They not only come from editors but also from organizers of technical conferences. Such specifications may require you to provide sections addressing certain topics in your report, such as experimental problems, environmental impact, decisions reached, budget estimates, and so on. The editors of an engineering journal may put limits on the number of words and the number of graphics for the technical paper. A word limit is frequently placed on the length of a proposal for a research grant, or an abstract as well as other sections of a document. Many reports have specifications that include requirements not only for their length but also for such matters as headings, spacing, and margins. Some government agencies, for example, require that proposals they receive be written in specific formats, in certain fonts, and even with restrictions on how many letters are permitted in each line of the text.

Knowing precisely what is expected before beginning to write will prevent wasted time and give the document better chances of success.

\section{VIII.READER-FRIENDLY TECHNICAL WRITING}

To get results, your communication must bridge the gap between you and your target audience. This gap is likely to be caused by variations in knowledge, ability, or interest. As an engineer, you may find yourself writing to a variety of people. Sometimes you will write to your professional and technical peers, sometimes to your superiors, and other times to those below you. In all these writing situations, inadequate audience analysis will inevitably result in noise (confusion), since different readers need different kinds of data. [3]

As a writer, you must organize your material so that each idea, point, and section is clearly and logically laid out within an appropriate overall pattern. There are several ways in which the reader-friendly quality orreadability of a document can be achieved.

First, as always, think before you write, and keep your readers firmly in mind. If your readers want to know what progress you have made on a project, what you did on a trip, or how to carry out a procedure, obviously they will expect your material in chronological order. If they are 
expecting the description of a piece of equipment or of the layout of some facilities, they should be provided with a description that logically moves from one physical point to another. On the other hand, if you have a number of points to make, such as five ways to reduce costs or six reasons why a project must be cancelled, present those points from the most important to the least important, or vice versa.

Second, perhaps your material needs to be presented in order of familiarity or difficulty, as when you are writing a tutorial or textbook. Or you may want to move from the general to the specific, as when you write a memo first stating that more stringent safety regulations are needed at your plant and then providing examples of current unsafe practices.

Third, there are other modes (patterns) of writing such as problem-solution, process, comparison and contrast, and so on, that a technical writer should consider using.

Fourth, other readability factors involve techniques of:

- making your ideas accessible (hierarchical headings, numbered headings, and paragraph length),

- using bulleted lists for some information,

- formatting pages carefully (margins, typeface, and white space),

- expressing clearly (ambiguity, vagueness coherence, directness),

- using efficient wording (wordiness, redundancy, turning verbs into nouns), and so on. [3]

Finally, editingand re-editing (for correct grammar, spelling and punctuation) by the author,peer-editing and collaboration(team writing),can further help make technical writing reader-friendly.

Rather than glance over the finished document once or twice to randomly find anything in need of improvement, take a more methodical approach to editing. Here is a two-step method you might consider using. First, the method recommends the author to check the document for technical accuracy. Second, it provides three levels of editing. Level 1: It is the nitty-gritty level of mechanics, grammar, spelling, punctuation and typos. At this level, you can use a good word processing program to provide you with suggestions on syntax and spelling. You as a writer must make the final choices on many of these options. Or, ask a friend or colleague who is well grounded in the basics of English. Level2: Look at your paragraph, sentence length and structure, possible verbiage, and precise word choice. Is the tone of your document appropriate? Have you used the active voice where possible? How about transitions, parallelism, and emphasis where called for. Level 3: This final level is the more global level of editing of the document, where you check the overall format, organization, and appearance. Is the work arranged the way it should be? Are specifications (if any) followed? Is it the right length? Have you used the best font size, margins, and spacing? Are headings, subheadings, lists, and graphics used effectively and consistently? Is the title page attractive? How about the packaging of the document, such as the quality of paper used, the binding, and the covers? [3]

\section{ETHICAL/LEGAL CONSIDERATIONS FOR THE TECHNICAL WRITER}

The technical writer sometimes encounterssome ethi$\mathrm{cal} /$ legal dilemmas on the job.First, technical writers must be familiar with the laws related to copyright, trademark, contract, and liability. He/she might be asked to write a document in such a way that it could mislead the reader. Therefore, the technical writer needs to understand areas of the law related to a writing task such as the following (proposals, etc.) becausehe/she may have to deal with ethical and legal pitfalls in words and graphics:

Proposals:The technical writer might be asked to exaggerate or lie about the organization's past accomplishments, pad the resumés of the project personnel, list as project personnel some workers who in fact will not be contributing to the project, or present an unrealistically short work schedule.

Progressreports: The technical writer might be asked to describe the project as proceeding smoothly, even though it is not.

Completion reports: The technical writer might be asked to change or leave out data that are inconsistent with the report's findings.

Product information: The technical writer might be asked to exaggerate the quality of products in catalogs or manuals or to downplay the hazards of using these products.

Websites: The technical writer might be asked to copy the source code of a competitor's site and then make minor changes so that you are not technically violating the competitor's copyright.

Graphics:The technical writer might be asked to hide an item's weaknesses in a photograph by manipulating the photo electronically. Or, he/she might be tempted to leave out some data in a graph, or even make up data. [8]

Further, understanding code of conduct that encourages ethical behaviour is an important part of technical communication on the job. Writing and implementing a code can be valuable because it forces an organization to clarify its own values and can foster an increased awareness of ethical issues.

Finally, a related issue is whistle-blowing. In an effort to overcome a dilemma, if the technical writer has exhausted all the resources at the organization, he/she can blow the whistle. That is, he/she can go public with information about serious unethical conduct within an organization. For example, an engineer blows the whistle if he/she tells a regulatory agency or a newspaper that quality-control tests on a company product were faked. [8] Ethicists argue that whistle-blowing is justified if the technical writer has tried to resolve the problem through internal channels and if whistle-blowing is reasonably certain to prevent or stop the wrongdoing.

In short, this paper has focused on technical writing as a skill for engineers. It has sought to define technical writing and throw light on the content and technique of writing the various components of successful technical reports (for example, articles, papers, or research reports, such as theses and dissertations). Then, it has highlighted other special features and principles of effective technical writing. The authors maintain that, for a journal article, conference paper, and research report to be effective, the writer must not only master the competence (skills and 
strategies) to write each of the sections or components of a technical report but alsobe able to incorporate some of the special features and principles elaborated on in the paper.

\section{REFERENCES}

[1] Gary Blake and Robert W. Bly, The Elements of Technical Writing. NewYork: Simon \& Schuster Macmillan Co. 2000.

[2] Mike Markel, Instructor's Resource Manual for $6^{\text {th }}$ Ed. Technical Communication. NewYork: Bedford/St. Martin's, 2001.

[3] DavidBeer and David McMurrey,A Guide to Writing as an Engineer. ( $2^{\text {nd }}$ ed.). John Wiley \& Sons, 2005.

[4] Leslie C. Perelman, James Paradis and Edward Barrett, the Mayfield Handbook of Technical \& Scientific Writing. Mountain View, CA: Mayfield Publishing Co., 1998.

[5] Heather Silyn-Roberts,Writing for Science and Engineering: Papers, Presentations, and Reports. Oxford: ButterworthHeinemann, 2000.

[6] Kathleen Mcmillan and Jonathan Weyers, How to Write Disserta tions \& Project Reports. $2^{\text {nd }}$ ed. London: Essex: Pearson Education Limited, 2011.
[7] Patrick McDonagh \& Jack Bordan (2000). Form \& Style: The Guide to Writing a Technical Report for Students in Engineering and Computer Science. Available at the following link: www.encs.concordia.ca/documents/Form\&Style.pdf. [Dec.2011].

[8] Mike Markel, Technical Communication. ( $7^{\text {th }}$ ed.). Boston: Bedford/St. Martin’s, 2004.

\section{AUTHORS}

Dr. Dheya Al-Othmany is with Nuclear Engineering, King Abdulaziz University, Jeddah, Saudi Arabia, E-mail: dothmany@kau.edu.sa

Dr. M. Solaiman Ali is with College of Engineering, King Abdulaziz University, Jeddah, Saudi Arabia, E-mail: m.s.ali.2009@gmail.com.

Received 19 April 2012. Published as resubmitted by the authors 24 June 2012. 